\title{
Application of Cognitive Load Theory in Accounting Education
}

\author{
Seedwell T. M. Sithole \\ Tasmanian School of Business \& Economics \\ University of Tasmania, Hobart, Australia \\ E-mail: seedwell.sithole@utas.edu.au
}

Received: October 7, 2018 Accepted: November 5, 2018 Published: November 6, 2018

doi:10.5296/ijafr.v8i4.13744

URL: https://doi.org/10.5296/ijafr.v8i4.13744

\begin{abstract}
The field of accounting education has recently adopted cognitive load theory (CLT), which originated in educational psychology. There are several empirical studies inspired by CLT which have demonstrated the practical implications of this theory. Although some articles have addressed the relationship of CLT and accounting education, none have considered the integration of the design principles and provide practical guidelines accounting educators may follow. Three techniques are described, by which educators may do so: (a) minimising instructional procedures that splits the attention of students, (b) tailoring instruction to levels of accounting students' expertise, and (c) minimising problem-solving exercises and utilising more worked examples. A detailed examination of these 3 techniques indicates that they assist students' understanding of accounting. These techniques are not applicable to all accounting learners but are more appropriate to accounting students learning a specific topic for the first time than to expert learners (e.g., final year students who have been introduced to the accounting topic). All 3 guidelines are based on the importance CLT places on the human cognitive architecture, particularly our knowledge of working and long-term memory, schema construction and automation, and the different types of cognitive load affecting the students to absorb and retain information.
\end{abstract}

Keywords: Accounting, Cognitive load theory, Education, Guidelines, Instruction

\section{Introduction}

The need to be aware of how students learn to enhance the quality of their learning has been identified in prior education literature (Abraham, 2006; Biggs 1988; Bobe \& Cooper, 2017). The results of how students learn have been identified in various studies (Abeysekera, 2011; 
Biggs 1990). As a result, there have been various models of student approaches to learning. For example, Biggs (1985) investigated initial research which demonstrated that most students learn not what educators think they should learn, but what students themselves perceive the task demands of them. Students who use a 'surface' approach to learning understand that a task would require specific answers to questions, consequently they rote learn. Students who use a 'deep' approach to learning would focus on themes and main ideas hence want to understand. Biggs (1985) assessed learners' use of these approaches. Since then, further investigation has been undertaken in terms of consequences and precedents of learning approaches of surface learning and deep learning (e.g. Everaert, Opdecam, \& Maussen, 2017). The above-mentioned studies consider the effectiveness of various learning approaches. We discuss cognitive load theory (CLT) and how it enhances learning by reorganising instructional material. CLT is an important theory because of the way it affects the design of accounting instruction material to accommodate the students' cognitive architecture.

Students studying accounting have difficulty understanding accounting partly because of the way instructional material is structured. This study aims to provide guidelines that enhance students learning using CLT principles. CLT researchers have developed various effects that involve reorganising the instructional material. Accounting educators implementation of the guidelines may reduce the overload on students' working memory capacity and improve students' performance in accounting.

The goal of accounting instructional material is to build transferable knowledge and skills to the workplace. The achievement of this goal requires instruction that is designed to make the most of human cognitive processes. Learning material that is structured according to human cognitive architecture enhances understanding while minimising processes that disrupt learning. Various studies in cognitive load theory over the past two decades have revealed several relevant effects that improve learning (Parte et al., 2018; Sithole et al., 2017; Wynder, 2017). Most of the instructional techniques were mainly demonstrated in educational psychology (e.g. Roodenrys et al., 2012), mathematics (e.g. Tindall-Ford et al., 2015), sciences (e.g. Rau, 2015), educational technology (Agostinho et al., 2013), medicine (Leppink, 2017) and many other disciplines. In this article, we provide an overview of cognitive load theory and guidelines derived from research that supports the use of specific instructional methods to foster those processes. The focus is on how to design instructional material in ways that best align with the known strengths and limitations of the human architecture.

A variety of theories from other fields have been adopted in accounting education. One recent example is cognitive load theory (CLT) which originated in educational psychology (Paas \& Ayres, 2014; Sweller, 2018; Sweller \& Paas, 2017). Cognitive load theory is based on the current understanding of a cognitive architecture consisting of a working memory (WM) that is limited in capacity to $4 \pm 1$ elements of information and duration of approximately 30 seconds when dealing with novel information (Cowan 2010; Miller 1956; Paas et al. 2003; Sweller et al. 2011). Cognitive load theory specifies learning as the development and automation of cognitive schemas stored in long-term memory (LTM) about content to be 
learnt such as a logical problem-solving procedure (Leppink, 2017). Various studies have demonstrated that the human working memory is limited (Barrouillet et al., 2007). The limitations of the human cognitive architecture are taken into account in the design principles of CLT (Leppink, 2017). Several empirical studies informed by CLT have contributed to guidelines for the design of accounting education instructional materials. Therefore, the purpose of this paper is twofold: to discuss several fundamental issues related to CLT principles and to provide accounting educators with three key guidelines for the design of instruction and assessment.

\section{Overview of Cognitive Load Theory}

In the 1980s, Sweller proposed cognitive load theory (CLT), a learning theory based on the human cognitive architecture model (Sithole et al., 2017; Schilling, 2016). This human cognitive architecture is composed of the working (short-term) memory and long-term memory (Sweller, 2011). The working memory system temporarily stores information and is a conscious processor incapable of holding large quantities of information. Its capacity is limited to only four to five meaningful elements of information at one time (Cowan, 2010). The recall of information in short term memory lasts for a few seconds. Working memory is necessary to keep things in mind while performing complex tasks such as comprehension reasoning, and learning (Baddeley, 2010). Since working memory is limited in storage capacity it requires careful design of instructional material to optimise its storage potential (Schilling, 2016). However, a larger storage system of the cognitive architecture is the long-term memory. This "powerful" long-term memory holds an unlimited number of elements (schemas) which cannot be consciously manipulated (Sweller, 2011). The learning mechanisms such as schema development and automation facilitate long-term memory (Sweller, 2008). If information cannot be processed beyond working memory, no meaningful learning occurs. Cognitive load theory is based on this knowledge of human cognitive architecture that assumes unlimited long-term memory and a limited working memory (Sweller, 2004). Instructional information has to be structured in a way that facilitates its transfer from short term memory to long term memory.

According to Paas et al. (2003), CLT is an instructional theory concerned with the interaction between the cognitive architecture and information structures. The way information is presented to students and the learning activities required of learners can cause cognitive overload. Cognitive overload occurs whenever the burden imposed on the student is unnecessary high thereby interfering with schema acquisition and automation. This type of overload presented by the way instructional material is designed is referred to as an extraneous cognitive load (Sithole et al., 2017). Paas et al. (2003) assert that most conventional instructional methods impose extraneous cognitive load since they were developed without considering the human cognitive architecture. For example, an instructional technique which requires students to employ a search and match process, this may occur when a student searches for referents in an explanation to a part on a diagram. Such formats of instruction may impose extraneous cognitive load on the learner since WM resources must be expended for activities that are irrelevant to schema acquisition and automation (Sweller, 2011). Schema refers to organized patterns of information that organizes 
categories of information and the relationships among them (Alexander \& Winne, 2006). These knowledge structures are held in long-term memory (Schilling, 2016).

The schema requires an active process to construct and automate and experienced learners (experts) enable schema acquisition through repetition of application (van Merrienboer \& Sweller (2005). This article describes the student's ability to better construct schema through instructional designs aligned to cognitive load theory. Schemas' mechanism for knowledge organization and storage can only be effective if instructional content is designed following the human cognitive architecture (Schilling, 2016).

Research on cognitive load theory has focused more on reorganizing instructional procedures to reduce extraneous cognitive load. Cognitive load theorists emphasize the need to reduce extraneous cognitive load when intrinsic cognitive load is high. Intrinsic cognitive load is the inherent level of difficulty associated with the nature of the material being learned, including the interactivity among the information elements. For example, solving a differential equation is inherently difficult compared to adding 2 to 3 . This inherent difficulty may not be altered by an educator. However, many schemas may be broken into individual chunks of information and taught separately (Paas et al., 2003). Therefore, when intrinsic cognitive load is low, there may be no need to attend to extraneous cognitive load since the total cognitive load imposed on the learner may not exceed WM capacity. Consequently, instructional techniques aimed to reduce cognitive overload have no effect when element interactivity is low.

Besides extraneous cognitive load and intrinsic cognitive load, CLT identifies another type of load called germane cognitive load. Germane cognitive load is effective for learning (Paas \& Van Gog, 2006). It involves investing cognitive resources to process element interactivity that has beneficial effects on learning (Phan et al., 2017). The way information is presented to students in their learning activities is relevant to the levels of germane cognitive load. Unlike extraneous cognitive load which interferes with students' learning, germane cognitive load enhances learning (Paas et al., 2003). As an alternative to WM resources being expended to search and match, germane cognitive load results in similar resources being used for schema acquisition and automation (Paas et al., 2003). Learning material needs to be designed in a way that minimises WM resources needed for cognitive processes that do not contribute to learning (Leppink, 2017; Sweller, 2010). There are various examples of cognitive processes that contribute to overload among novice learners.

\section{Guidelines for the Design of Instruction and Assessment in Accounting}

\subsection{Guideline (1): Minimising Instructional Procedures That Splits the Attention of Students}

An instructional design that splits attention contributes to an unnecessary process resulting in a student dividing attention between several information sources commonly referred to as the split-attention effect (Schroeder \& Cenkci, 2018). Split-attention effect occurs when required pieces of information are presented separately rather than together (Ayres and Sweller 2014; Sithole, 2016). One possible solution to minimise cognitive overload presented by split-attention involves integrating the spatially separated material into a single source (Sithole 
\& Abeysekera, 2017). An example of instructional content that was formatted in a different way that decreases split-attention by bringing the text as close as possible to the diagram (integrating) is shown in Table 2. Several studies have demonstrated that integrated material as shown in Table 2, is much more effective than split-attention material shown in Table 1 (e.g., Agostinho et al., 2013; Roodenrys et al., 2012; Sithole \& Abeysekera, 2017; Tindall-Ford et al., 2015).

Table 1. Example of conventional split-attention format found in textbooks

\begin{tabular}{ll}
\hline & Assets \\
\hline DR & CR \\
$(+)$ & $(-)$ \\
\hline
\end{tabular}

Note: To increase (+) the balance in the asset accounts, you debit by entering the amount on the left hand side. To decrease (-) the balance you credit by entering the amount on the right hand side. Debits to a specific asset account should exceed the credits to that account. The normal balance of an account is on the side where an increase in the account is recorded. Thus asset accounts normally have debit balances.

Source: Sithole \& Abeysekera (2017)

Table 2. Example of integrated format

Assets

DR

$(+)$

To increase (+) the balance in the asset by entering accounts, you debit by entering the amount on the left hand side. The normal balance of an account is on the side where an increase in the account is recorded. Thus asset accounts normally have debit balances. Debits to a specific asset account should exceed the credits to that account.
$\mathrm{CR}$

$(-)$

To decrease (-) the balance you credit the amount on the right hand

Source: Sithole \& Abeysekera (2017)

However, the split-attention effect eventually disappears when students become more competent. For example, integrating various components of the accounting equation may reduce cognitive overload for learners encountering the material for the first time. For more advanced learners (e.g. final year accounting students), such integration is not needed and, in some instances, may even contribute to extraneous cognitive load (Sweller, 2011).

Careful consideration of the split-attention effect and intrinsic cognitive load is important, 
because settings in accounting education may contribute to extrinsic cognitive load. Accounting educators should take into consideration that when students refer to multiple sources of information they may trigger ineffective problem-solving search activity that does not contribute to learning

\subsection{Guideline (2): Tailoring Instruction to Levels of Accounting Students' Expertise}

One of the key concepts in cognitive load theory is the extent of instructional material's element interactivity (Blayney, Kalyuga, \& Sweller, 2015; Sweller, 2010). The level of element interactivity is influenced by the degree to which learning elements can be understood in combination with other elements or only individually (Blayney et al. 2015). When instructional elements interact with other elements, they must all be acquired at the same time resulting in a high WM load. When an element is learnt separately from other elements since there is no interaction with them, element interactivity would be very low. The levels of element interactivity is not only dependent on the attributes of the information being processed but is also depended on the level of expertise of the student. For example, high element interactive instructional material for a novice learner may constitute very low element interactivity for expert students.

When designing instructional material multiple elements that interact should be isolated (Johnson \& Slayter, 2012). In an introductory accounting context, Johnson and Slayter (2012) illustrated that appropriate instructional design can be achieved by decreasing the complexity of the learning task, initially limiting the scope of accounting transaction types. In an auditing subject, when students are asked to go through elements of the audit process such as risk assessments, interviewing, testing and analysis, process documentation, and reporting from start to finish and backwards a high cognitive load is experienced due to multiple elements interacting.

The way that students deal with multiple elements depends on their level of expertise. When novice learners practice with a simulated client in an authentic simulated workplace environment (i.e., bringing an expert accounting practitioner into the classroom), students will probably experience a higher intrinsic cognitive load than when we let them practice outside such an environment (i.e. with another student as an accounting 'expert', because in the latter situation there is no environmental stimuli to pay attention to (Tremblay et al., 2017). For expert learners, cognitive overload may not arise. In most accounting processes, it is not adequate to simply learn the step by step processes. It is recommended that students initially undertake step by step processes before learning the interrelationships. For example, learning steps from journal entries up to the trial balance and financial statements ensures that interactivity does not add to intrinsic cognitive load. Understanding accounting processes where there are many steps involved may increase intrinsic cognitive load for novice students. For expert learners, a lower intrinsic cognitive load may be experienced because more advanced accounting students can activate more developed automated cognitive schemas than their less experienced colleagues. 
3.3 Guideline (3): Minimise Problem-Solving Exercises by Utilising More Worked Examples

Several studies in accounting education have emphasised the importance of worked examples and in schema creation (Halabi, Tuovinen, \& Farley, 2005; Mostyn, 2011). According to Wynder and Luckett (1999) worked examples are of interest to novice accounting learners as they represent a significant source for understanding accounting concepts without the need to use detailed written or verbal instructions. An investigation of the location of explanations regarding computerised decision aid in taxation found that the attainment of knowledge is increased when explanations are available as worked examples (Rose \& Wolfe, 2000).

From a cognitive load theory perspective, since learners have limited processing capacity, proper allocation of cognitive resources is essential to learning (Sweller, 2011). Presenting instruction as worked examples assist with schema construction and automation more than problem solving exercises. When using a problem-solving process, learners are given a asked to work out a solution from a given problem with minimum or no guidance from the teacher.

Worked examples exist where steps to solving a question are presented before a learner completes similar problems (Halabi, Tuovinen, \& Farley, 2005; Kalyuga, Chandler, and Sweller 2001). Previous research has demonstrated that worked examples are a more effective form of guided practice than problem solving questions alone (Halabi et al., 2005; Salden et al., 2010). In these studies, worked examples have enhanced facilitation of learning while there has been a decrease in cognitive load when compared to conventional problem solving.

Applying these results leads us to recommend that students should complete many worked examples first before proceeding to problem solving exercises since worked examples enable students to operate with lower levels of cognitive load (effort) than students completing the problem-solving exercises.

\section{Conclusion}

The guidelines presented in this study aim to enhance students learning in accounting. The difficulty that students face in understanding accounting is partly caused by the way instructional material is structured. One way which addresses this challenge is to reorganize the instructional material following CLT principles. Thus, if accounting educators implement the approaches highlighted in the above guidelines, students learning may be enhanced. Educators will be guided on principles that do not overload students working memory capacity to improve students' performance in accounting.

How students learn and how to enhance students' learning has been based on various theories and philosophies. Unlike other theories, CLT uses the human cognitive architecture and empirical support to recommend instructional design principles. The complexity and quantity of the instructional material, as well as the way it is delivered are key factors that determine whether information can be transferred from working memory to long term memory thereby enhancing the students learning while minimizing cognitive overload in the working memory. The introduction of CLT in accounting education has facilitated contemporary methods of instruction in accounting education. Results from empirical and theoretical work on CLT and its implications for accounting education, has provided opportunities for instructional 
guidelines highlighted in this paper. Although the widespread knowledge and application of CLT in accounting education remains a major challenge, the instructional guidelines presented in this paper are based on extensive empirical research over the years in accounting and other disciplines.

We suggest that accounting educators should use instructional techniques that support human learning processes, particularly the management of cognitive load. Research in the past 20 years involving cognitive load has provided many principles for designing instruction that enhances the learning process. The techniques recommended in this paper are among the key reorganizations that have worked in accounting education.

\section{References}

Abeysekera, I. (2011). Learning financial accounting in a tertiary institution of a developing country: An investigation into instructional methods. Journal of University Teaching \& Learning Practice, 8(1).

Abraham, A. (2006). Teaching and learning in accounting Education: Students' perceptions of the linkages between teaching context, approaches to learning and outcomes. In Juchau, R., \& Tibbits, G. (Eds.), Celebrating Accounting. University of Western Sydney.

Agostinho, S., Tindall-Ford, S., \& Roodenrys, K. (2013). Adaptive diagrams: Handing control over to the learner to manage split-attention online. Computers \& Education, 64(2013), 52-62.

Alexander, P. A., \& Winne, P. H. (Eds.) (2006). Handbook of Educational Psychology (2nd ed.). Mahwah, NJ: Lawrence Erlbaum Associates.

Ayres, P., \& Sweller, J. (2014). The split-attention principle in multimedia learning. In R. E. Mayer (Ed.), The Cambridge Handbook of Multimedia Learning (2nd ed., pp. 206-226). New York: Cambridge University Press.

Baddeley, A. D. (2010). Working Memory. Current Biology, 20(4), 136-140.

Barrouillet, P., Bernardin, S., Portrat, S., Vergauwe, E., \& Camos, V. (2007). Time and cognitive load in working memory. Journal of Experimental Psychology: Learning, Memory, and Cognition, 33(3), 570.

Biggs, J. B. (1985). The role of metalearning in study processes. British Journal of Educational Psychology, 55, 185-212.

Biggs, J. B. (1988). Assessing student approaches to learning. Australian Psychologist, 23, 197-206.

Biggs, J. B. (1990). Teaching design for learning. In B. Ross (Ed.), Teaching for Effective Learning (pp. 11-26). Higher Education Research and Development Society of Australasia.

Blayney, P., Kalyuga, S., \& Sweller, J. (2015). Using Cognitive Load Theory to Tailor Instruction to Levels of Accounting Students' Expertise. Journal of Educational Technology \& Society, 18(4), 199-210. 


\section{Mll Macrothink}

International Journal of Accounting and Financial Reporting

ISSN 2162-3082

2018, Vol. 8, No. 4

Bobe, B. J., \& Cooper, B. J. (2017). The effect of language proficiency on approaches to learning and satisfaction of undergraduate accounting students. Accounting Education, 1-23.

Cowan, N. (2010). The magical mystery four: how is working memory limited, and why? Curr Dir Psychol Sci., 19(1), 51-57.

Everaert, P., Opdecam, E., \& Maussen, S. (2017). The relationship between motivation, learning approaches, academic performance and time spent. Accounting Education, 26(1), 78-107.

Halabi, A. K., Tuovinen, J. E., \& Farley, A. A. (2005). Empirical Evidence on the Relative Efficiency of Worked Examples versus Problem-Solving Exercises in Accounting Principles Instruction. Issues in Accounting Education, 20(1), 21-32.

Johnson, B., \& Slayter, E. (2012). Impact of structure of early practice on student performance in transaction analysis. Issues in Accounting Education, 27, 101-112.

Kalyuga, S., Chandler, P., \& Sweller. J. (2001). Learner experience and efficiency of instructional guidance. Educational Psychology, 21(1), 5-23.

Leppink, J. (2017). Cognitive load theory: Practical implications and an important challenge. Journal of Taibah University Medical Sciences, 12(5), 385-391.

Miller, G. (1956). The magical number seven, plus or minus two: some limits on our capacity for processing information. Psychol Rev, 63, 81-97.

Mostyn, G. R. (2011). Cognitive load theory: What it is, why it's important for accounting instruction and research. Issues in Accounting Education, 27(1), 227-245.

Mousavi, S. Y., Low, R., \& Sweller, J. (1995). Reducing cognitive load by mixing auditory and visual presentation modes. Journal of Educational Psychology, 87(2), 319.

Paas, F., Renkl, A., \& Sweller, J. (2003). Cognitive load theory and instructional design: recent developments. Educ Psychol, 38, 1-4.

Parte, L., Garvey, A. M., \& Gonzalo-Angulo, J. A. (2018). Cognitive Load Theory: Why It's Important for International Business Teaching and Financial Reporting. Journal of Teaching in International Business, 29(2), 134-160.

Phan, H. P., Ngu, B. H., \& Yeung, A. S. (2017). Achieving optimal best: Instructional efficiency and the use of cognitive load theory in mathematical problem solving. Educational Psychology Review, 29(4), 667-692.

Rau, M. A. (2015). Enhancing undergraduate chemistry learning by helping students make connections among multiple graphical representations. Chemistry Education Research and Practice, 16, 654-669.

Roodenrys, K., Agostinho, S., Roodenrys, S., \& Chandler, P. (2012). Managing one's own cognitive load when evidence of split-attention is present. Applied Cognitive Psychology, 26(6), 878-886. 


\section{$\triangle 1$ Macrothink}

International Journal of Accounting and Financial Reporting

ISSN 2162-3082

2018, Vol. 8, No. 4

Rose, J. M., \& Wolfe, C. J. (2000). The effect of system design alternative on the acquisition of tax knowledge from a computerized tax decision aid. Accounting Organizations and Society, 25(3), 285-306.

Schilling, J. F. (2016). Cognitive Load Theory of Learning: Underpinnings and Model. International Journal of Athletic Therapy \& Training, 21(2), 12-16.

Schroeder, N. L., \& Cenkci, A. T. (2018). Spatial Contiguity and Spatial Split-Attention Effects in Multimedia Learning Environments: a Meta-Analysis. Educational Psychology Review, 30(3), 679-701

Sithole, S. T. (2016). The effects of presentation formats on understanding financial accounting: an experimental study. Australasian Accounting Business \& Finance Journal, 10(2), 76-92.

Sithole, S. T. M., \& Abeysekera, I. (2017). Accounting education: a cognitive load theory perspective. Routledge.

Sithole, S., Chandler, P., Abeysekera, I., \& Paas, F. (2017). Benefits of guided self-management of attention on learning accounting. Journal of Educational Psychology, 109(2), 220-232.

Sweller, J. (2008). Instructional implications of David C. Geary's evolutionary educational psychology. Educational Psychologist, 43(4), 214-216.

Sweller, J. (2010). Element interactivity and intrinsic, extraneous and germane cognitive load. Educational Psychology Review, 22(2), 123-138.

Sweller, J. (2011). Cognitive load theory. Psychology of Learning and Motivation, 55, 37-76. Academic Press.

Sweller, J. (2018). Measuring cognitive load. Perspectives on medical education, 7(1), 1-2.

Sweller, J., \& Paas, F. (2017). Should self-regulated learning be integrated with cognitive load theory? A commentary. Learning and Instruction, 51, 85-89.

Sweller, J., Ayres, P., \& Kalyuga, S. (2011). Cognitive Load Theory (Vol. 1). New York: Springer.

Tindall-Ford, S., Agostinho, S., Bokosmaty, S., Paas, F., \& Chandler, P. (2015). Computer-based learning of mathematical concepts by studying instructor-managed or selfmanaged split-attention materials. Education Technology and Society (Online).

Tremblay, M. L., Lafleur, A., Leppink, J., \& Dolmans, D. H. (2017). The simulated clinical environment: cognitive and emotional impact among undergraduates. Medical Teacher, 39(2), 181-187.

Wynder, M. (2017). Visualising accounting concepts: insights from Cognitive Load Theory for English as a Second Language students. Accounting Education, 1-23.

Wynder, M. B., \& Luckett, P. F. (1999). The effects of understanding rules and a worked 


\section{Macrothink \\ International Journal of Accounting and Financial Reporting ISSN 2162-3082 2018, Vol. 8, No. 4}

example on the acquisition or procedural knowledge and task performance. Accounting and Finance, 39(2), 177-203.

\section{Copyright Disclaimer}

Copyright for this article is retained by the author(s), with first publication rights granted to the journal.

This is an open-access article distributed under the terms and conditions of the Creative Commons Attribution license (http://creativecommons.org/licenses/by/4.0/) 